\title{
ELECTRONIC HEALTH RECORD (EHR) ADOPTION IN SOUTH AFRICAN HEALTHCARE CENTRES: A CASE OF NW PROVINCE
}

\author{
Thatoyaone Modise ${ }^{1}$, Nehemiah Mavetera ${ }^{1}$ and Mmaki Jantjies ${ }^{2}$ \\ ${ }^{I}$ North West University P Bag X 2046 Mmabatho $2735+27-76151868$ \\ ${ }^{2}$ University of Western Cape Department of Information Systems South Africa
}

\begin{abstract}
Electronic Health Records (EHRs) enable the healthcare sector to enjoy increased efficiency and throughput, whilst cutting overhead costs in healthcare centres. The aim of this study was to investigate the adoption of EHRs in South Africa by identifying the factors that influence their rate of adoption within healthcare institutions. The Theory of Planned Behaviour (TPB), Diffusion of Innovation (DoI) Theory and the Technology Acceptance Model 2, (TAM2) are used as the theoretical lenses through which this problem was viewed.

Results showed support for some of the factors of TPB, TAM2 and DoI, namely Relative Advantage, Output Quality, Result Demonstrability, Computer Self-Efficacy, System Complexity and Enjoyment/Job Satisfaction. A new variable - Patient Safety Endangerment - was also found to have a significant influence on the healthcare worker's decision to use a particular EHR. It is with this information that a better understanding of how EHRs are used in the North West Province can be established and this information can be used by decision makers when implementing similar systems to maximise their adoption.
\end{abstract}

\section{KEYWORDS}

Electronic Health Records, Technology Acceptance Model, Theory of Planned Behaviour, Diffusion of Innovations Theory, National Health Insurance, South Africa

\section{INTRODUCTION}

Patient records in South African healthcare facilities are semi-electronic (with the exception of public clinics) (South African Department of Health, 2012). The electronic systems used in public hospitals tend to mostly cater for Hospital Administrative duties as patient medical records are still kept in filing cabinets. The majority of public clinics have no electronic system at all.

South Africa is making efforts to increase access to quality healthcare for all its citizens, and doing away decentralized health records by introducing a National Health Insurance (NHI) fund [South African Department of Health, 2012; Mayosi and Benatar, 2014; Mayosi et. al, 2009]. At the heart of this fund is a national e-Health system that will handle all patient information and reporting (South African Department of Health, 2012). Electronic systems of any kind have been known to increase efficiencies and throughput, as well as reduce overhead costs of doing business, however these systems add no value if they are not utilized. This negates all the efforts that were taken to develop such systems. EHRs in particular have the potential to improve availability, continuity of care, empowerment, patient safety, and quality of care [Chib et al, 2008; Gartner, 2009; Ruxwana, Herselman, and Conradie, 2010].

This study provides an investigation into the adoption of technologies used in healthcare facilities. This is done to help identify possible barriers impeding the use of a healthcare patient administration system once developed, to ensure that new e-health systems do not suffer from low adoption. Factors identified as impeding adoption can be addressed in future e-Health systems to ensure maximal adoption by system users and ultimately provide the patient with the intended benefits resulting from the use of the technology. 


\section{REVIEW OF RELATED LITERATURE}

TPB is a revision of the Theory of Reasoned Action (TRA) constructed by Ajzen \& Fishbein, (1980). According to TRA, an individual's intention to perform a behaviour is a combination of their attitude towards performing the behaviour and subjective norms (Ajzen \& Fishbein, 1980). The construction of TPB includes an extra construct namely Perceived Behavioural Control (PBC) which is based on two beliefs: control beliefs and their perceived facilitation. The Technology Acceptance Model (TAM) is also a derivative of TRA. According to Holden and Ben-Tzion (2009: p2) "TAM was developed in the 1980's, in light of concern that workers were not using IT made available to them".

TAM dictates that a person's acceptance of an Information System (IS) lies in their intention to use it. The intention, can be determined by taking into account a person's attitude toward the IS in question, and their perceptions concerning its usefulness. Attitudes towards the IS are a result of the beliefs that a person holds about the IS. Mathhews (2012: p1) further elaborates that "External variables, such as the task, user characteristics, political influences, organizational factors, and the development process, are expected to influence technology acceptance behaviour indirectly by affecting beliefs, attitudes, or intentions."

TRA/TPB have been used to predict adoption of a broad range of activities including but not limited to smoking, exercise, condom use, and moral behaviour [Paula, Modia, and Patel, 2016; Kangas, et al., 2015; Yzer et al., 2015]. TAM on the other hand was created solely to predict use in the IT context. In an article by Chuttur, (2009), the author explains how TPB provides more details that can be used to explain the intention of participants to use a computer application when compared to TAM. The added predictive power of TPB stems from the addition of the construct PBC. This construct is what allows for the identification of barriers that impede system use such as limitations on user's skills.

TAM2 (Venkatesh and Davis, 2000), a derivative of TAM identifies several variables including those already identified in TAM. TAM2 takes into consideration the individual as well as organizational context, thus making it better suited (when compared to TAM), to explain software use in the workplace. When compared to TPB, TAM2 takes into account factors that an employee or employer would take into consideration before adopting a technology in the workplace. However, researchers have found that facilitating conditions have a more direct influence on the behaviour itself. This makes sense as no matter how high the intention to use a technology, that action cannot be carried out if there is a barrier standing in the way of the potential user.

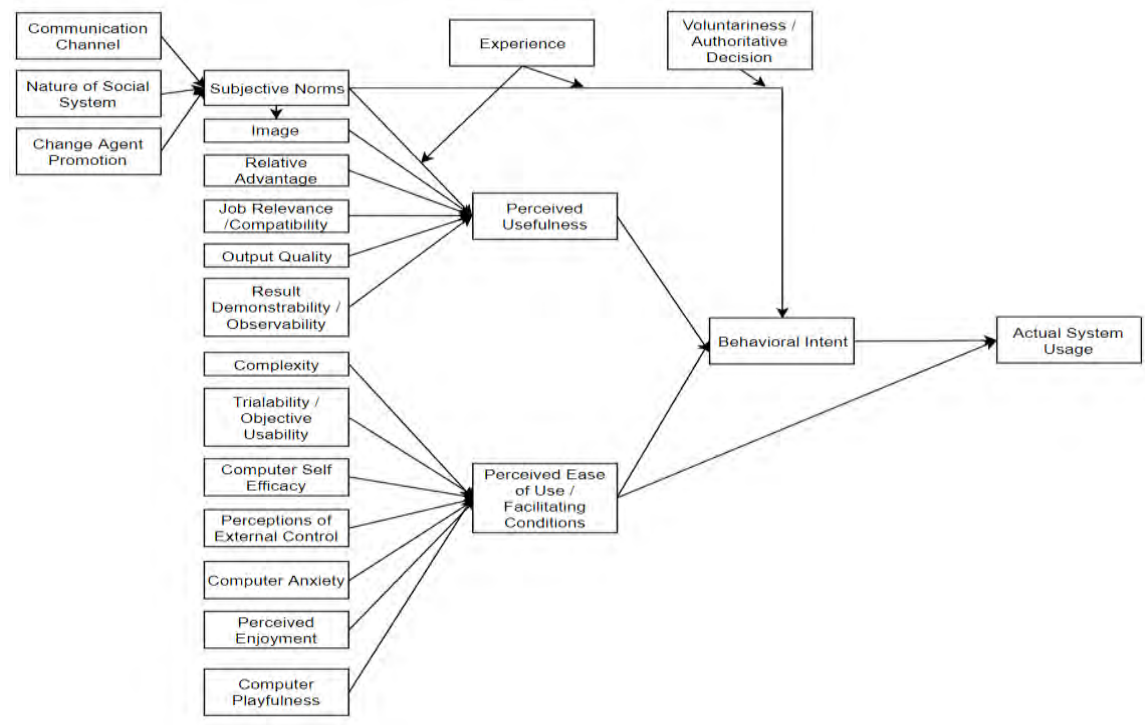

Figure 1. Conceptual model of this study

Another aspect of adoption that is explored in this study is the innovativeness of the innovation. By this we refer to attributes (features) of the innovation itself that persuade the potential user to adopt the innovation. To explain this, we turn to the Diffusion of Innovations (DoI) theory. The theory identifies five (5) innovation design variables namely: relative advantage, compatibility, complexity, trialability, and 
observability that, according to the theory have an influence on whether an innovation is adopted and how quickly its adoption will spread. These factors from DoI, TAM2 as well as TPB have been combined to form a conceptual model that was utilised by this study. The diagram shown depicts this conceptual model.

Structurally, it can be seen that the conceptual model bears many similarities to TAM2 with the addition of DoI innovation attributes. The review of the determinants of TRA, TPB, TAM, TAM2 \& DoI as well as their provided definitions revealed several overlapping attributes. Such attributes included Job Relevance \& Compatibility, Result Demonstrability \& Observability, Voluntariness \& Authoritative Decisions, and Trialability \& Objective Usability. To avoid measuring attributes that seemed to be duplicates, these attributes were then grouped together to produce only one attribute. Unique attributes from DoI and TPB were added to TAM2 under the existing constructs of Perceived Usefulness and Perceived Ease of Use so as to supplement the predictive power of these constructs.

\section{RESEARCH QUESTIONS}

The following are research questions that this study aims to answer.

i. What are the factors that influence the adoption of EHRs in the North West Province?

ii. How can the adoption of EHRs in South Africa be improved?

\section{RESEARCH METHODOLOGY}

It has become best practice that when conducting any form of TPB research, the researcher must identify key factors having an influence on the subject under discussion (Ajzen, 2002). For quality and reliability, the factors identified must be independent of researcher input. To ensure this, this research study utilised a mixed methods approach. This means that both the qualitative and quantitative methodology were utilised to collect the data required for this study in a specific order.

The strategy employed in our case is referred to as a sequential exploratory research strategy and ensures that the salient beliefs responsible for influencing the individual's decision to use EHRs, were determined in the initial phase of the study using interviews and confirmed by respondents through the use of a questionnaire at the last stage.

Data from the interviews with the participants was recorded and later transcribed. Using thematic analysis, the transcribed interviews were analysed and coded according to the coding framework made up of the innovation attributes from the conceptual model. New themes were identified from the data and added to the framework.

\section{RESULTS}

\subsection{Qualitative Investigation}

The main intention of the qualitative phase of the study was to identify the salient beliefs for the main innovation attributes of our conceptual model. The table below shows the beliefs that were identified for the main constructs of the study.

Table 1. Salient beliefs identified from Interviews with participants

\begin{tabular}{|c|c|c|c|}
\hline Construct & Behavioural Intent & Subjective Norms & $\begin{array}{l}\text { Perceptions of External Control } \\
\text { (Facilitating Conditions) }\end{array}$ \\
\hline $\begin{array}{l}\text { Salient Beliefs } \\
\text { Identified }\end{array}$ & $\begin{array}{ll}- & \text { Patient Safety } \\
& \text { Endangerment }\end{array}$ & $\begin{array}{ll}\text { - } & \text { Co-workers Influence } \\
\text { - } & \text { Family Influence } \\
\text { - Supervisor Influence }\end{array}$ & $\begin{array}{ll}\text { - } & \text { Incomplete Functionality } \\
\text { - } & \text { Electricity Outages } \\
\text { - Network Outages } \\
\text { - }\end{array}$ \\
\hline
\end{tabular}


The interviews with the participants helped identify new factors that were not initially in the conceptual model. Some factors were identified as not being applicable to the study. The Construct Image, defined as "the degree to which an innovation is perceived to enhance one's status in one's social system" (Venkatesh, and Bala, 2008), was not supported and was subsequently removed from the conceptual model. Respondents highlighted the fact that there was no prestige associated with using the patient administration system at their workplace as all administrative staff had the same access to it. It is for this reason that the Image Attribute was discarded from the model.

\subsection{Hypotheses and Questionnaire Construction}

The conceptual model of this study is made up of a number of factors identified from TPB, TAM2 and DoI. Following the qualitative investigation that resulted in a revised conceptual model, hypotheses, and subsequently sets of questions, were documented for each innovation attribute of the model to construct the hypotheses of this study, as well as the questionnaire to be used by this study.

\subsection{Instrument Reliability}

The table below contains the alpha values of those measures. Of the 21 measures, reliability was computed for eleven (11) of the measures. The other ten (10) measures had a single question determining that measure and as such, reliability could not be computed. Of the 11 measures whose reliability was computed, two (2) displayed unacceptable reliability: Experience $(\mathrm{N}=2$, alpha $=.109)$ and Communication Channels $(\mathrm{N}=3$, alpha $=-.204)$. The other nine (9) measures showed an alpha value between .648 and .991, demonstrating fair to high reliability.

The Experience measure presented a low alpha of $(\mathrm{N}=2$, alpha $=.109)$, this was attributed to users who indicated that they had no prior encounters with systems similar to the one at their workplace. The same users also indicated that a lack of experience would not let it deter them from using the system in their workplace. The two contrasting responses were not anticipated at the time of instrument design and thus resulted in the low alpha value.

Communication Channels $(\mathrm{N}=3$, alpha $=-.204)$ also presented a low alpha as well. An inspection of the question items revealed that the questions evaluated "which of the two communication mediums (e-mail or contact sessions) did users prefer to be informed about new systems in their workplace". These questions evaluated two different forms of communication and as such the responses to these question items were not consistent with one another.

The low alphas observed in Experience and Communication Channels were as a result of a lack of unidimensionality in the questions measuring those scales. Unidimensionality in Cronbach's Alpha assumes that the questions are only measuring one latent variable or dimension (StatisticsHowTo, 2014) These two measures were, however, not discarded from the instrument based on their alpha values as they were still valid measures of adoption, their questions were simply rectified to ensure unidimensionality.

\subsection{Hypotheses Testing}

Correlational analysis is a technique that deals with relationships among variables. According to Cohen, West and Aiken, (2014) multivariate correlation analysis or sometimes multiple correlation analysis is a technique that may be used "whenever a quantitative variable, the dependent variable (Y), is to be studied as a function of, or relationship to, any factors of interest, the independent variables (IVs)". Multivariate correlational analysis was used in this case to evaluate the nature of the relationship between the identified innovation attributes and the usage of EHRs at healthcare facilities of the North West Province.

The table below contains the hypotheses of this study and the results from the testing of those hypotheses. Although the direction of the relationship between the influencing components on the influenced components could be estimated, a two-tailed test of significance was taken to try to remove the probability of error in this assumption. A value of .05 was used as the significance value as is widely used in academic research (Gelman, 2012). Correlation analysis of the hypothesis of this study were as follows. 
Table 2. Correlation Analysis of Study

\begin{tabular}{|c|c|c|c|}
\hline \multirow{2}{*}{ (H)\# } & \multicolumn{2}{|c|}{ Correlation } & \multirow{2}{*}{ Supported } \\
\hline & $\mathrm{R}$ & Sig. (2-tail) & \\
\hline 1 & .091 & .704 & No \\
\hline 2 & .076 & .749 & No \\
\hline 3 & .269 & .252 & No \\
\hline 4 & .163 & .481 & No \\
\hline 5 & .132 & .570 & No \\
\hline 6 & .433 & .050 & Yes \\
\hline 7 & .496 & .022 & Yes \\
\hline 8 & .558 & .009 & Yes \\
\hline 9 & .490 & .024 & Yes \\
\hline 10 & -.268 & .241 & No \\
\hline 11 & .279 & .221 & No \\
\hline 12 & .045 & .848 & No \\
\hline 13 & .343 & .127 & No \\
\hline 14 & -.051 & .825 & No \\
\hline 15 & .304 & .181 & No \\
\hline 16 & .132 & .570 & No \\
\hline 17 & -.250 & .274 & No \\
\hline 18 & .400 & .072 & No \\
\hline 19 & .638 & .002 & Yes \\
\hline 20 & -.512 & .018 & Yes \\
\hline 21 & .596 & .004 & Yes \\
\hline 22 & .668 & .001 & Yes \\
\hline 23 & .725 & $<.000$ & Yes \\
\hline
\end{tabular}

The results of the correlations revealed that Relative Advantage, Output Quality and Result Demonstrability were statistically significant in determining Perceived Usefulness. Experience (E) and Voluntariness (V) were hypothesized to have a mediating effect on Subjective Norm and Perceived Usefulness. Direct correlations between Subjective Norm (SN) and Perceived Usefulness (PU) yielded a strong correlation (SN-PU: $\mathrm{r}=.533 ; \mathrm{p}=.013$ ).

The Perceived Ease of Use component was hypothesized to be influenced by Change Management, Complexity, Trialability, Computer Self-Efficacy, Perceptions of External Control, Perceived Enjoyment and Computer Anxiety. For all of these components of Perceived Ease of Use, none of them were found to be statistically significant.

A new component, Patient Safety Endangerment, was found to have a statistically significant and negative effect on Behavioural Intention $(r=-.512, p=.018)$. Essentially, the higher the chances of the system endangering the safety and privacy of the patient, the less likely the intention of potential users to use such a system.

Further exploration of the correlation data found relationships between influencing variables and the main variables (Perceived Usefulness, Perceived Ease of Usefulness, Behavioural Intention and Actual System Usage). Complexity $(r=-.663, p=.001)$, Computer Self-Efficacy $(r=.593, p=.007)$ and Computer 
Playfulness $(r=.634, p=.002)$ were found to have a relationship that was statistically significant with Actual System Use. This relationship was strange as it had been expected that these factors would contribute towards the ease of use of the system and not the actual usage. That being said, the effects of these factors cannot be overlooked as they hold some merit. The implication is that these factors have the ability to impede actual usage of a system regardless of the attitudes the user may have towards the usage of the system.

Actual System Use was defined in this study as the frequency in which healthcare workers utilised the patient administration at their workplace daily. It then follows that the usability of a system will most likely suffer a loss in terms of the usage frequency if that system is substantially or highly complicated.

Table 3. Correlation Values between Actual System Use and other factors

\begin{tabular}{|c|c|c|c|}
\hline & Complexity & Computer Self-Efficacy & Computer Playfulness \\
\hline Actual System Use (r) & -.663 & .593 & .634 \\
\hline S ig. (2-tailed) & .001 & .007 & .002 \\
\hline
\end{tabular}

The table above contains the correlation between factors that were hypothesized to have a relationship with Perceived Ease of Use but were instead found to have a statistically significant relationship with Actual System Use.

\section{DISCUSSION}

\subsection{What are the Factors that Influence the Adoption of EHRs in Healthcare Facilities?}

Amongst all of the innovation attributes investigated, there were some whose definitions seemed to be referring to the same thing, or overlapping each other. These attributes were combined into a single attribute instead. Those attributes included: Job Relevance and Compatibility, Result Demonstrability \& Observability, Voluntariness \& Authoritative Decisions, and Trialability \& Objective Usability.

From the hypothesized relationships between the adoption attributes of this study, some attributes were found to be supported by this study, while others were not. Those attributes whose hypothesized relationship was not found to be significant were subsequently dropped from the model. Having analysed all the above, the initial conceptual model is then refined to produce the following model in Figure 3 below:

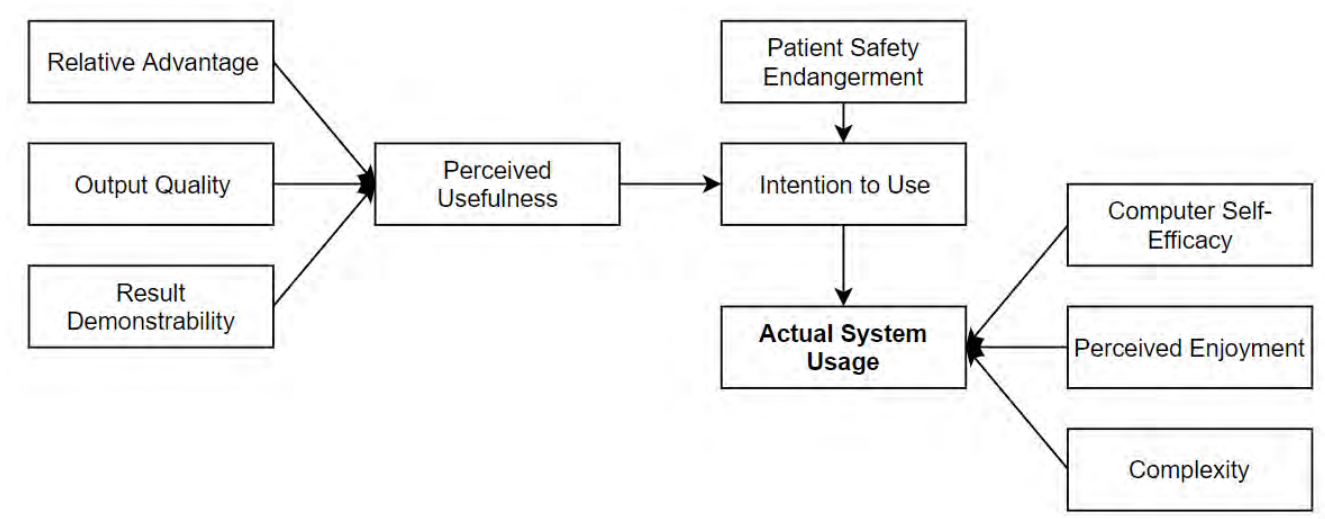

Figure 2. Revised Conceptual Model

The revised conceptual model has less factors than those of the initial model which is acceptable, as not all of the hypothesized factors were found to be supported by the study. Complexity, Computer Self-Efficacy and Perceived Enjoyment are seen having a more direct influence on Actual System Usage. A new factor, Patient Safety Endangerment, is also identified as having a direct influence on the intention of a user to use the patient administration system at their workplace. Relative Advantage, Output Quality and Result 
Demonstrability are the only determinants that were identified as having a significant influence on the perceived usefulness of the patient administration system. Subjective Norms and its determinants, Voluntariness, Experience, and Job Relevance were found to be non-significant. The hypothesized determinants of Perceived Ease of use: Trialability, Perceptions of External Control, Computer Anxiety, and Perceived Enjoyment were also found to be non-significant.

\subsection{How can the Adoption of EHRs be Improved in South African Healthcare Facilities?}

This section proposes recommendations on ways in which the use of EHRs in healthcare facilities in South Africa can be maximized. The recommendations stem from literature and empirical data that was collected as part of this study.

i. Involvement of Staff

Management needs to interact with their staff before proposing upgrades or new implementations, particularly staff that utilizes the EHR system on a daily basis, as these users have in-depth knowledge of any pitfalls, the system they work with may have, when it comes to the work they do.

This form of involvement and transparency in the workplace decreases resistance and has been found to increase productivity levels as well as a range of other workplace and worker characteristics (Walden et al., 2015).

Staff are also positioned to provide insights that could assist in the design, testing and customization of the proposed system and its workflow (Jeffrey, 2016). Staff can also be utilized to provide feedback of their daily usage to aid in the optimization and modification of the proposed system and workflow (Blavin al., 2013).

ii. System Functionality and User Interfaces

Ensure that the systems being procured provide functionality that is relevant to the job functions of the staff that will use it, produces results that are in-line with expectations of management as well as ensures that benefits that arise from the use of the system are clear to the user - as per the Perceived Usefulness attributes put forward by this model. Functionality that is currently not available in the systems in healthcare facilities needs to be included.

iii. Change Management

Change Management is defined as the process of continually renewing the direction of an organisation, its structure as well as capabilities in order to serve the ever-changing needs of its customers (Nassif, Capretz, and Ho, 2010).

As part of the change management plan, training is one of the most popular interventions to increasing the ease of use of a system. "Training offers a good opportunity to help users adjust to the change that has been introduced by [any] system, and helps build positive attitudes toward the [new system]" (Munassar, and Govardhan, 2010: p271). Training introduces the new users of a technology to how the new system looks and functions. This helps reduce the view that the target group may have regarding the complexity of the system.

iv. Creating and Hiring Digital Natives

Seeing how the use of technology is increasing in the healthcare sector, it follows that healthcare facilities must ensure that their staff are familiar with the role that computers play in their lives. Training courses on end-user computing are widely available in South Africa, which staff members with no computing experience can be made to attend. The integration of introductory computing courses in the curriculum of students pursuing careers in the healthcare sector could also add to maximising their efficacy and playfulness around computers.

\section{CONCLUSION}

Several factors from the conceptual model were not supported by the data collected and were thus not considered for the revised model. Of the factors that emerged from the qualitative phase of the study, Patient Safety Endangerment - defined in this study as the degree to which a system could potentially endanger and/or compromise the safety and privacy of the patient - was found to be statistically significant to the study and thus, was included in the revised model. Interventions to reduce or alleviate the problematic factors and maximise those factors that increase adoption have been put forward with the hopes that management will take these into consideration. 


\section{REFERENCES}

Ajzen, I., \& Fishbein, M. (1980). Understanding attitudes and predicting social behaviour. EnglewoodCliffs, NJ: Prentice-Hall

Ajzen, I., 2002. Perceived behavioral control, self-efficacy, locus of control, and the theory of planned behavior 1 . Journal of applied social psychology, 32(4), pp.665-683

Blavin, F., Ramos, C., Shah, A., \& Devers, S. 2013. Lessons from the Literature on Electronic Health Record Implementation. Urban $\quad$ Institute $\quad$ Retrieved $04 \quad$ April $2016 \quad$ from https://www.healthit.gov/sites/default/files/hit_lessons_learned_lit_review_final_08-01-2013.pdf

Chib, A., Lwin, M.O., Ang, J., Lin, H. 2008. Midwives and mobiles: using ICTs to improve healthcare in Aceh Besar, Indonesia. Asian Journal of Communication. Volume 18, Issue 4, 2008. Availability http://www.tandfonline.com/doi/citedby/10.1080/01292980802344182

Chou, H., Huang, Y., Wu, M., \& Weng, Y. 2011. TAM2-based Study of Website User Behavior-Using Web 2.0 Websites as an Example.

Chuttur M.Y. (2009). "Overview of the Technology Acceptance Model: Origins, Developments and Future Directions," Indiana University, USA. Sprouts: Working Papers on Information Systems, 9(37). http://sprouts.aisnet.org/9-37

Cohen, P., West, S.G. and Aiken, L.S., 2014. Applied multiple regression/correlation analysis for the behavioral sciences. Psychology Press.

Department of Health. 2012. E-Health strategy South Africa: 2012-2016. Pretoria: Government Printer.

Gartner, 2009, eHealth for a Healthier Europe, Swedish Ministry of Health and Social Affairs

Gelman, A., 2012. What do statistical p-values mean when the sample= the population? Statistical Modeling, Causal Inference, and Social Science, 26.

Holden, Richard J., and Ben-Tzion Karsh. "A theoretical model of health information technology usage behaviour with implications for patient safety." Behaviour \& Information Technology 28.1 (2009): 21-38.

Jeffrey, D.A., 2016. Testing the technology acceptance model 3 (TAM 3) with the inclusion of change fatigue and overload, in the context of faculty from Seventh-day Adventist universities: A revised model. Andrews University.

Kangas, J. L., Baldwin, A. S., Rosenfield, D., Smits, J. A. J., Rethorst, C. D. 2015. Examining the moderating effect of depressive symptoms on the relation between exercise and self-efficacy during the initiation of regular exercise. Health Psychology, Vol 34(5), May 2015, 556-565. http://dx.doi.org/10.1037/hea0000142

Mathhews, S. 2012. Technology Acceptance Model (TAM). Viewed on 17 March 2016 from http://smatts.blogspot.co.za/2012/08/technology-acceptance-model-tam.html

Mayosi, B.M. and Benatar, S.R., 2014. Health and health care in South Africa-20 years after Mandela. New England Journal of Medicine, 371(14), pp.1344-1353.

Mayosi BM, Lawn JE, van Niekerk A, Bradshaw D, Abdool Karim SS, Coovadia HM. Health in South Africa: changes and challenges since 2009. Lancet 2012; 380:2029-43.

Munassar, N.M.A. and Govardhan, A., 2010. A comparison between five models of software engineering. IJCSI, 5, pp.95-101.

Nassif, A.B., Capretz, L.F. and Ho, D., 2010, January. Software estimation in the early stages of the software life cycle. In International conference on emerging trends in computer science, communication and information technology pp. 5-13.

Paula, J., Modia, A.; Patel, J. 2016. Predicting green product consumption using theory of planned behaviour and reasoned action. Journal of Retailing and Consumer Services. Vol 29, March 2016, pp 123-134

Ruxwana, N.L., Herselman, M.E., and Conradie, D.P. 2010. ICT Applications as e-Health Solutions in Rural Healthcare in the Eastern Cape Province of South Africa [online]. Health Information Management Journal, Vol. 39, No. 1, 2010: 17-29. Availability: http://search.informit.com.au/documentSummary;dn=961281654549031;res=IELAPA

StatisticsHowTo. 2014. Cronbach's Alpha: Simple Definition, Use and Interpretation. Retrieved 15 January 2018 from http://www.statisticshowto.com/cronbachs-alpha-spss/

Venkatesh, V. and Bala, H. 2008. Technology acceptance model 3 and a research agenda on interventions. Decision sciences, 39(2), pp. 273-315.

Venkatesh, V. and Davis, F.D., 2000. A theoretical extension of the technology acceptance model: Four longitudinal field studies. Management science, 46(2), pp.186-204.

Walden, D.D., Roedler, G.J., Forsberg, K., Hamelin, R.D. and Shortell, T.M., 2015. Systems engineering handbook: A guide for system life cycle processes and activities. John Wiley \& Sons.

Yzer, M., Weisman, S., Mejia, N., Hennrikus, D., Choi, K., \& DeSimone, S. 2015. Informing Tobacco Cessation Benefit Use Interventions for Unionized Blue-Collar Workers: A Mixed-Methods Reasoned Action Approach. Prevention Science. August 2015, Volume 16, Issue 6, pp 811-821 